\title{
ESFORÇOS TRATÓRIOS NO ARRANCAMENTO DE CAFEEIROS ( $\left.{ }^{1}\right)$
}

\author{
MAMOR FUJIWARA $\left({ }^{2}\right)$, JAIR ROSAS DA SILVA ( ${ }^{(3)}$, \\ EDISON MARTINS PAULO $\left({ }^{4}\right)$, FLÁVIO BUSSMEYER ARRUDA $(5,7)$ \\ e DOMINGOS ANTÔNIO MONTEIRO $\left(^{6}\right)$
}

\begin{abstract}
RESUMO
Um método alternativo para arrancamento de cafeeiros $\hat{e}$ apresentado neste trabalho: consiste ele em uma garra arrancadora presa ao cafeeiro e tracionada por trator. Determinaçōes realizadas no Centro Experimental de Campinas, em latossolo roxo, em fevereiro de 1984, demonstraram que o esforço médio requerido foi de $2.127 \mathrm{kgf}$ por planta para $C$. canephora $\mathrm{L}$. cv. Robusta e de $1.158 \mathrm{kgf}$ por planta para $C$. arabica L. cv. Mundo Novo. Dentre os sistemas utilizados, o mais indicado foi o arrancamento de três cafeeiros sucessivamente, alinhados no sentido tratório em esforços independentes, numa só operação. Sua utilização propiciou menor movimento de solo do que no uso de trator com lâmina. Foi possivel o emprego de um trator de pneus de potência de $100 \mathrm{cv}$.
\end{abstract}

Termos de indexação: café, arranquio, implemento.

(1) Trabalho apresentado no XI Congresso Brasileiro de Pesquisas Cafeeiras, realizado em Londrina (PR), em 22-25 de outubro de 1984. Recebido para publicação em 16 de maio de 1985. pinas, $S P$.

(2) Seção de Movimentação do Solo, Instituto Agronômico (IAC), Caixa Postal 28, 13001 Cam-

(3) Seçāo de Projetos e Materiais, IAC.

(4) Divisāo de Estaçōes Experimentais, IAC.

(5) Seção de Irrigação e Drenagem, IAC.

$\left({ }^{6}\right)$ Seção de Raízes e Tuberrculos, IAC.

(7) Bolsista do CNFq. 


\section{INTRODUÇÃO}

A renovação dos cafezais tem sido uma prática de interesse, devido à disponibilidade de material genético de alto potencial produtivo, aliada ao fato de que a aplicação de modernas técnicas agronômicas em cafezais velhos, plantados em alinhamentos e espaçamentos inadequados, desprotegidos da erosão e localizados em regiōes ecologicamente impróprias, não responderia economicamente às adubações químicas e orgânicas a às irrigações (TOSELLO \& REIS, 1961; TOSELLO et alii, 1962, e FIBGE, 1975).

Para o arrancamento do cafezal, normalmente são empregados tratores de esteiras dotados de lâminas (CAMPINAS, 1966) ou correntão tracionado por dois tratores de esteiras (CARMO, 1980), além de outros métodos. Para as condições da lavoura, tal investidura encontra dificuldades, representadas pela carência de equipamento pesado e pessoal técnico treinado. Esses trabalhos, por via de regra contratados a terceiros, devido à natureza dos equipamentos empregados $e$ das condiçōes em que são realizados, caracterizam uma operação de desmatamento, induzindo custos operacionais elevados. $O$ trator agrícola existente na fazenda seria uma alternativa na sua execução.

Assim, procurou-se preencher essa lacuna com a construção e ensaio de um protótipo de garra arrancadora manual, acoplada à unidade tratora por meio de cabos de aço, destinada a abarcar firmemente o tronco do cafeeiro e possibilitar-Ihe $o$ arrancamento por tracionamento.

Não foram localizadas referências sobre determinação de esforços tratórios exigidos e tempos consumidos em trabalhos de arrancamento de cafeeiros.

\section{MATERIAL E MÉTODOS}

O estudo foi realizado no Centro Experimental de Campinas, do Instituto Agronômico (IAC), em fevereiro de 1984, em latossolo roxo, de declividade menor que $3 \%$ e com as seguintes características físicas para a camada $0-50 \mathrm{~cm}$ :

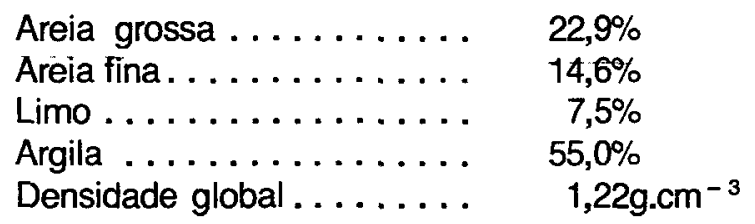

Os teores médios de umidade do solo durante as determinaçōes foram de $24,1,23,2$ e $24,3 \%$, respectivamente, para as camadas de $0-10,10-25$ e 25-50 cm, próximos à capacidade de campo. 
Os cafeeiros eram das espécies Coffea canephora L. cv. Robusta e Coffea arabica L. cv. Mundo Novo, de um ensaio de progênies da Seção de Genética do IAC. As plantas tinham doze anos de idade e porte entre 2,5 e 3,0 m de altura, apresentando diâmetro do fuste (ponto de engate da garra) entre 12 e $25 \mathrm{~cm}$, com os diâmetros maiores correspondendo ao cafeeiro Robusta. O plantio das duas espécies foi feito no espaçamento de $3 \times 2 \mathrm{~m}$, com um pé por cova.

As garras arrancadoras, construídas nas oficinas da Divisāo de Engenharia Agrícola do IAC, possibilitam a firme fixaçāo e o tracionamento individual dos cafeeiros, sendo dotadas de mecanismo baseado no principio de alavanca, que impede sua abertura uma vez iniciado o tracionamento.

Como unidades de tração, foram empregados:

a) trator com rodado de pneus, traçāo traseira, marca Massey Ferguson, modelo 95X, com potência bruta no motor de $100 \mathrm{cv}$ a $2.200 \mathrm{rpm}$;

b) trator com rodado de esteiras, marca Fiat, modelo $60-\mathrm{Cl}$, com potência máxima no motor de $48 \mathrm{cv}$.

Para determinação dos esforços tratórios exigidos, foi utilizado um dinamógrafo de tração dotado de sistema de molas, marca Lohmann-Tarnogrocki, cujo registrador é acionado por dispositivos de relojoaria, com capacidade para $5.000 \mathrm{kgf}$, e, para medição dos tempos consumidos no arrancamento, um cronômetro marca Zivy, com leitura de 0,1 segundo.

Preliminarmente, foi realizado um arrancamento convencional com trator de esteiras dotado de lâmina não angulável, para possibilitar o acesso ao local da lavoura selecionado para início do ensaio.

O cafeeiro Robusta foi arrancado, utilizando-se as garras acopladas a tratores de rodas e de esteiras. Em ambos os casos, foram determinados esforços individuais para uma, duas ou três plantas, em quatro repetiçōes, num processo de arrancamento em seqüência, de tal modo que, ao findar a remoção de uma planta, já se iniciava a remoçāo da seguinte, sem paralisação da máquina. No segundo caso, foram também determinados os esforços tratórios múltiplos, ou seja, para duas ou três plantas removidas simultaneamente.

O cafeeiro Mundo Novo foi arrancado apenas com o trator de rodas, extraindo-se uma ou duas plantas de forma sucessiva e duas ou três covas, de forma simultânea, sempre numa mesma operação.

Os cafeeiros foram arrancados no sentido das linhas de plantio, tomando-se ao acaso o método a ser empregado. Foram anotados o tempo consumido e o esforço de tração requerido para o arrancamento.

O arrancamento convencional, para a comparação dos tempos, foi feito com trator de esteiras e lâmina não angulável em 25 cafeeiros Robusta. 


\section{RESULTADOS E DISCUSSÃO}

Os resultados obtidos encontram-se no quadro 1, e detalhes da garra arrancadora e dos tratores em operação, na figura 1.

As condições de umidade do solo, próximas à capacidade de campo, foram adequadas para a operaçāo de arrancamento dos cafeeiros. Supōe-se que isso tenha contribuído para diminuição dos esforços exigidos.

As espécies $C$. canephora L. cv. Robusta e C. arabica L. Cv. Mundo Novo, da mesma idade, exigiram forças de tração diferentes para arrancamento individual. O Robusta exigiu, em média, um esforço tratório cerca de $80 \%$ superior ao do Mundo Novo, respectivamente 2.127 e 1.158 kgf por planta. Esse acréscimo parece estar relacionado ao maior sistema radicular e diâmetro do fuste do primeiro.

QUADRO 1. Esforços individuais e múltiplos requeridos e tempos consumidos no arrancamento de cafeeiros

\begin{tabular}{|c|c|c|c|c|c|}
\hline \multirow{2}{*}{ Cultivar } & \multirow{2}{*}{$\begin{array}{l}\text { Unidade de potência } \\
\text { e implemento }\end{array}$} & \multirow{2}{*}{$\begin{array}{c}\text { Número de } \\
\text { plantas }\end{array}$} & \multirow{2}{*}{$\begin{array}{l}\text { Arrancamento } \\
\text { em seqüêencia }\end{array}$} & \multicolumn{2}{|c|}{ Arrancamento simultânec } \\
\hline & & & & Esforço & Tempo \\
\hline \multirow{10}{*}{ Robusta } & \multirow{5}{*}{$\begin{array}{c}\text { Trator de esteiras } \\
\text { e garras }\end{array}$} & & kgf/planta* & $\mathrm{kgf}$ & s \\
\hline & & 1 & 2.088 & - & - \\
\hline & & 2 & 2.025 & - & - \\
\hline & & 3 & 2.200 & - & - \\
\hline & & Média & 2.104 & - & - \\
\hline & \multirow{4}{*}{$\begin{array}{c}\text { Trator de rodas } \\
\text { e garras }\end{array}$} & 1 & 2.371 & - & - \\
\hline & & 2 & 2.275 & 3.438 & 130 \\
\hline & & 3 & 1.800 & 4.290 & 250 \\
\hline & & Média & 2.149 & - & - \\
\hline & $\begin{array}{c}\text { Trator de esteiras } \\
\text { e lâmina }\end{array}$ & 25 & - & - & 470 \\
\hline \multirow{4}{*}{ Mundo Novo } & \multirow{4}{*}{$\begin{array}{c}\text { Trator de rodas } \\
\text { e garras }\end{array}$} & 1 & 1.175 & - & - \\
\hline & & 2 & 1.140 & 1.625 & - \\
\hline & & 3 & - & 1.500 & - \\
\hline & & Média & 1.158 & - & - \\
\hline
\end{tabular}

* Médias de duas a seis repetições. 

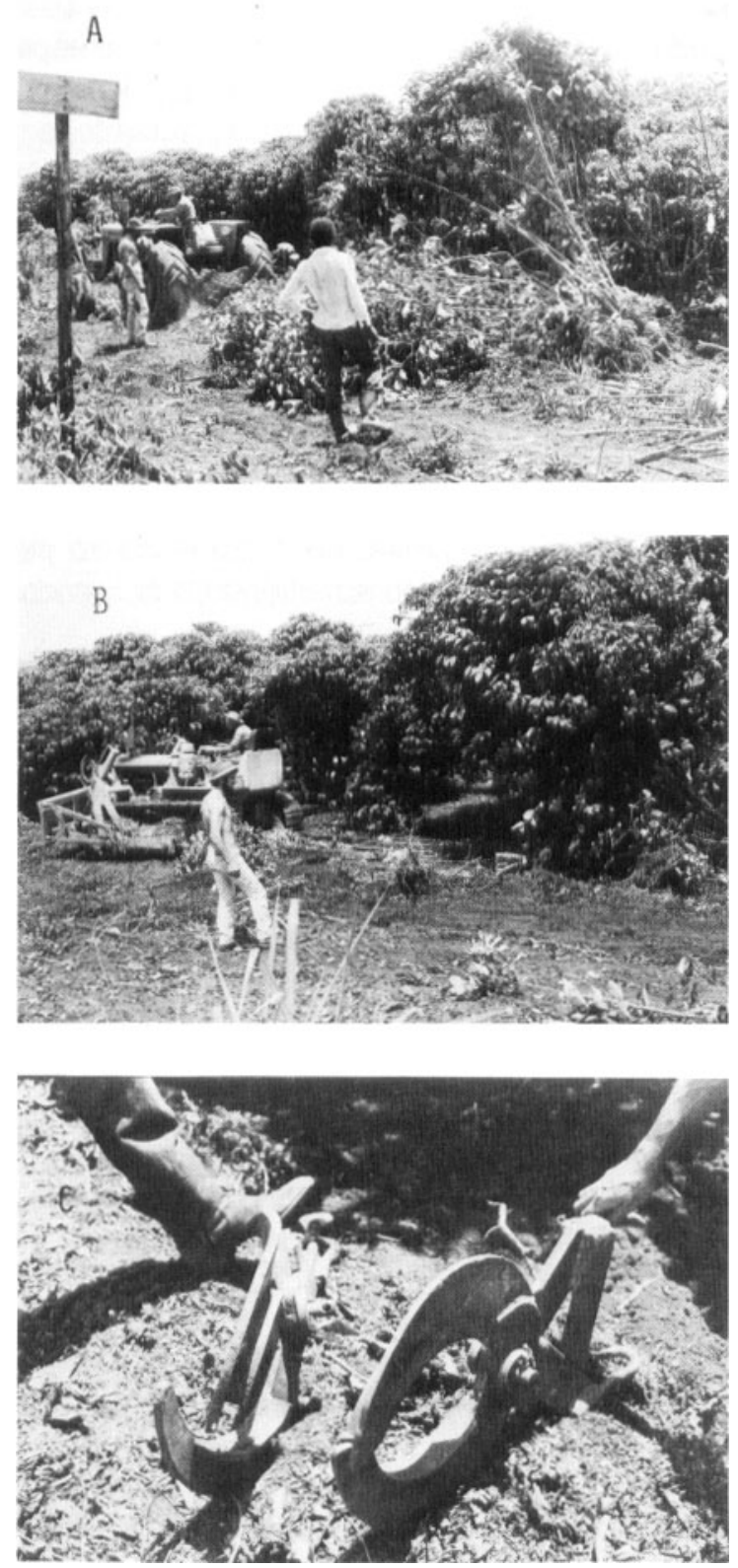

FIGURA 1. Vistas da área de ensaio e da garra arrancadora. A: trator de pneus em operação com a garra; B: trator de esteiras em operação com a garra; C: garras arrancadoras. 
O trator de esteiras com lâmina não angulável apresentou o menor tempo de operação, cerca de 18 segundos por planta, em média, ao passo que o melhor tempo com o uso da garra foi de cerca de 65 segundos por planta. Por outro lado, no primeiro sistema de arrancamento, foi observada grande movimentação do solo, sendo necessário posterior nivelamento da superfície para futuras operações agrícolas. A garra arrancadora visa efetuar o serviço de erradicaçāo do cafeeiro com mínima movimentação do solo e conseqüente redução dos esforços tratórios necessários à operação. Assim, são minimizadas a desestruturação e a predisposição do solo à erosão.

Observaçōes preliminares sobre o sistema de erradicação dos cafeeiros - arrancamento simultâneo de duas ou três plantas e remoção em direção perpendicular, em ângulo e paralela à linha de plantio - permitiram selecionar aquele feito paralelamente à linha como o mais conveniente. Dentre os dois sistemas com garra ensaiados no arrancamento sucessivo de três cafeeiros em uma só operação, o que utilizou trator de esteiras foi o mais indicado, devido ao menor esforço requerido por planta. Os resultados desta comparação obtidos com o Mundo Novo indicam o contrário, provavelmente devido ao pequeno número de medições realizadas no arrancamento simultáneo, não sendo esses resultados conclusivos.

A exigência de esforço tratório para arrancamento simultâneo de duas ou três covas de cafeeiros é função da resultante do sistema de forças formado, dependendo, portanto, do comprimento dos cabos de aço, dos ângulos formados entre eles e do ângulo vertical formado com o eixo de deslocamento do trator.

Os esforços tratórios despendidos pelos dois tipos de tratores diferiram no máximo em $14 \%$, sendo os resultados ligeiramente favoráveis ao trator agrfcola com rodado de pneus, no arrancamento simultâneo.

O trator de pneus, cujo esforço de tração máximo no ensaio foi de cerca de $2.650 \mathrm{kgf}$, impossibilitando o arrancamento simultâneo de duas ou três covas do cafeeiro Robusta, pode, no entanto, ser empregado nos outros sistemas.

Dados do censo de 1970 (FIBGE, 1975) mostram que apenas $3,6 \%$ das propriedades agrícolas paulistas dispōem de trator de esteiras. Assim, 0 trator de rodas nelas disponivel pode ser usado em mais uma atividade agrícola - a de renovação gradual da lavoura cafeeira - que possibilitará, ainda, a redução do seu custo horário de depreciação.

O trator de esteiras mostrou-se adequado para executar o arrancamento de cafeeiros Mundo Novo ou Robusta em todos os sistemas ensaiados, à exceção do emprego de lâmina. Do ponto de vista da vida útil desse trator, recomenda-se o arrancamento em seqüência para o cultivar Robusta, ou seja, com esforços tratórios sucessivos.

O protótipo da garra arrancadora resistiu aos esforços de tração mencionados e desempenhou satisfatoriamente sua função. Os tempos médios consumidos registrados no arrancamento sucessivo ou simultâneo foram considerados satisfatórios para a execução da operação em nivel de lavoura. 


\title{
4. CONCLUSŌES
}

O cafeeiro Robusta exigiu cerca de $80 \%$ a mais de esforço tratório médio para arrancamento individual, em relação ao cultivar Mundo Novo, ambos com doze anos de idade, em latossolo roxo.

Um trator agrícola de pneus ( $100 \mathrm{cv}$ ) e outro de esteiras ( $48 \mathrm{cv}$ ) mostraram-se adequados para realizar o arrancamento sucessivo de duas ou três covas de cafeeiros Mundo Novo ou Robusta, por este método. O trator de esteiras foi capaz de executar a mesma operação também de forma simultânea.

Dentre os processos ensaiados, o de arrancamento sucessivo de três cafeeiros, alinhados no sentido de deslocamento do trator, em esforços independentes (uma planta por vez) foi o que se mostrou mais eficiente.

A garra arrancadora associada aos tratores de rodas ou de esteiras demonstrou boa operacionalidade, sendo viável o uso desses conjuntos na renovação gradual de cafezais.

O emprego do trator de rodas em mais uma operação agrícola poderá contribuir para reduzir seu custo horário de depreciação.

\section{SUMMARY}

\section{POWER REQUIREMENT FOR COFFEE PLANT UPROOTING}

\begin{abstract}
A new method for removing perennial plants is presented in this paper. It consists of using a clamp type of tool that is attached to a plant and pulled by a tractor. A study was conducted in Campinas, State of São Paulo, Brazil, in February of 1984 with a 12 year old coffee plantation on Dusk Red Latosol. The average effort required for coffee plants uprooting was $2,127 \mathrm{kgf} /$ plant for $C$. canephora L. cv. Robusta and $1,158 \mathrm{kgf} / \mathrm{plant}$ for C. arabica L. cv. Mundo Novo. Among the several systems tested, the best was the use of three clamps applying individual effort in a successive remotion of three plants in one unique operation. This system had the advantage of smaller soil movement than the traditional use of bulldozer. The use of a $100 \mathrm{hp}$ wheel tractor was feasible for this system, and it presented a good performance of operation.
\end{abstract}

Index terms: coffee, plant uprooting, implement.

\section{REFERÊNCIAS BIBLIOGRÁFICAS}

CAMPINAS. Instituto Agronômico. Divisão de Engenharia Agrícola. Relatório do exercício de 1965. Jundiaí, 1966. 22p.

CARMO, A.J.B. Panorama da mecanização agrícola no Estado de São Paulo. In: CICLO DE ESTUDOS SOBRE MECANIZAÇÃO AGRÍCOLA, 1., Jundiaí. Anais. Campinas, Instituto Agronômico, Divisão de Engenharia Agrícola, 1980. p.9-29. 
FUNDAÇÃO INSTITUTO BRASILEIRO DE GEOGRAFIA E ESTATÍSTICA, Rio de Janeiro. Censo Agropecuário, 1970. Rio de Janeiro, 1975. (Série Regional)

TOSELLO, R.N.; ALOISI SOBRINHO, J.; CASTRO, G.A.P. \& ABRAMIDES, E. Contribuiçāo ao estudo da irrigação e da restauraçāo de lavoura velha de café. II. Resultados da Estação Experimental de Pindorama. Bragantia, Campinas, 21:523-570, 1962.

\& REIS, A.J. Contribuição ao estudo da irrigação e restauração de lavoura velha de café. I. Resultados da Estação Experimental de Ribeirão Preto. Bragantia, Campinas, 20:997-1044, 1961. 